OPEN ACCESS

Edited by:

LiZUo,

Ohio State University, USA

Reviewed by:

Xuejun Wang,

University of South Dakota, USA

Steven Cala,

Wayne State University, USA

Fan Ye,

University of Florida, USA

Kunihiro Sakuma,

Toyohashi University of Technology,

Japan

*Correspondence:

Séverine Lamon

severine.lamon@deakin.edu.au

Specialty section:

This article was submitted to

Striated Muscle Physiology,

a section of the journal

Frontiers in Physiology

Received: 15 October 2015 Accepted: 11 January 2016 Published: 08 February 2016

Citation:

Wallace MA, Della Gatta PA, Ahmad Mir B, Kowalski GM, Kloehn J,

McConville MJ, Russell AP and Lamon S (2016) Overexpression of

Striated Muscle Activator of Rho Signaling (STARS) Increases C2C12 Skeletal Muscle Cell Differentiation. Front. Physiol. 7:7.

doi: 10.3389/fphys.2016.00007

\section{Overexpression of Striated Muscle Activator of Rho Signaling (STARS) Increases C2C12 Skeletal Muscle Cell Differentiation}

\author{
Marita A. Wallace ${ }^{1}$, Paul A. Della Gatta ${ }^{1}$, Bilal Ahmad Mir ${ }^{1}$, Greg M. Kowalski ${ }^{1}$, \\ Joachim Kloehn ${ }^{2}$, Malcom J. McConville ${ }^{2}$, Aaron P. Russell ${ }^{1}$ and Séverine Lamon ${ }^{1 *}$ \\ ${ }^{1}$ Centre for Physical Activity and Nutrition Research, School of Exercise and Nutrition Sciences, Deakin University, Burwood, \\ VIC, Australia, ${ }^{2}$ Department of Biochemistry and Molecular Biology, Bio21 Institute of Molecular Science and Biotechnology, \\ University of Melbourne, Parkville, VIC, Australia
}

Background: Skeletal muscle growth and regeneration depend on the activation of satellite cells, which leads to myocyte proliferation, differentiation and fusion with existing muscle fibers. Skeletal muscle cell proliferation and differentiation are tightly coordinated by a continuum of molecular signaling pathways. The striated muscle activator of Rho signaling (STARS) is an actin binding protein that regulates the transcription of genes involved in muscle cell growth, structure and function via the stimulation of actin polymerization and activation of serum-response factor (SRF) signaling. STARS mediates cell proliferation in smooth and cardiac muscle models; however, whether STARS overexpression enhances cell proliferation and differentiation has not been investigated in skeletal muscle cells.

Results: We demonstrate for the first time that STARS overexpression enhances differentiation but not proliferation in $\mathrm{C} 2 \mathrm{C} 12$ mouse skeletal muscle cells. Increased differentiation was associated with an increase in the gene levels of the myogenic differentiation markers $\mathrm{Ckm}, \mathrm{Ckmt2}$ and Myh4, the differentiation factor lgf2 and the myogenic regulatory factors (MRFs) Myf5 and Myf6. Exposing C2C12 cells to CCG-1423, a pharmacological inhibitor of SRF preventing the nuclear translocation of its co-factor MRTF-A, had no effect on myotube differentiation rate, suggesting that STARS regulates differentiation via a MRTF-A independent mechanism.

Conclusion: These findings position STARS as an important regulator of skeletal muscle growth and regeneration.

Keywords: skeletal muscle, proliferation, differentiation, myogenesis, regeneration

\section{INTRODUCTION}

Pre- and post- natal skeletal muscle development and regeneration of mature adult skeletal muscle require the coordinated control of myocyte proliferation and differentiation (Buckingham et al., 2003; Bentzinger et al., 2012). Each stage of muscle cell development and maturation is precisely regulated by the basic helix-loop-helix (bHLH) E-box binding protein family of myogenic regulatory factors (MRFs; Zhang et al., 1995; Kablar et al., 1997; Perry and Rudnick, 2000; Yokoyama and Asahara, 2011). Serum response factor (SRF) is a MADS box protein 
that interacts with MRFs to further enhance myoblast proliferation and myotube differentiation (Black and Olson, 1998; Pipes et al., 2006b; Yokoyama and Asahara, 2011). SRF regulates cytoskeletal dynamics, myogenic gene expression and myocyte proliferation and differentiation via the transcriptional control of immediate early genes such as Fos, Lif, Junb and Egr1, as well as via muscle specific genes including actin and myosin (Chai and Tarnawski, 2002; Pipes et al., 2006b; Miano et al., 2007). Attenuating SRF activity disrupts myoblast proliferation and differentiation (Soulez et al., 1996), while SRF knockdown impairs skeletal muscle development in vivo (Zhang et al., 2001; Li et al., 2005). Identifying the molecular factors that regulate SRF activity is therefore essential to comprehend the mechanisms underlying skeletal muscle development and regeneration.

Among the known SRF regulators, striated muscle activator of Rho signaling (STARS; also known as MS1 and ABRA) is a muscle specific actin binding protein that associates with the Iband, Z-disk and M-line of the sarcomere (Arai et al., 2002). In conjunction with RhoA, STARS increases actin polymerization, resulting in the nuclear translocation of the SRF transcriptional co-activator myocardin-related transcription factor-A (MRTFA) and enhanced SRF transcriptional activity (Arai et al., 2002; Kuwahara et al., 2005). STARS is responsive to mechanical stress and its expression increases in rodent cardiac muscle in response to pressure overload and in rabbit smooth muscle following fluid shear-induced arteriogenesis (Mahadeva et al., 2002; Kuwahara et al., 2007; Troidl et al., 2009). In human skeletal muscle, we and others have shown that STARS is increased in response to resistance and endurance acute exercise and exercise training (Lamon et al., 2009; MacNeil et al., 2010; Wallace et al., 2011). STARS may therefore act as a sensor to transduce extracellular mechanical stress signals to activate the molecular pathways regulating muscle development, growth and regeneration. STARS is transcriptionally regulated by MEF2, MyoD, PGC- $1 \alpha / E R R \alpha$ and SRF, transcription factors playing multiple roles in myocyte proliferation and differentiation (Naya and Olson, 1999; Handschin et al., 2003; Kuwahara et al., 2007; Ounzain et al., 2008; Murray and Huss, 2011; Wallace et al., 2011; Chong et al., 2012). In addition, STARS can regulate its own expression via a feed-forward mechanism that requires SRF binding to the serum response element (SRE) located on the STARS promoter (Chong et al., 2012). STARS is expressed during skeletal muscle early embryonic development and its expression increases during post-natal muscle development (Arai et al., 2002; Peng et al., 2008; Chong et al., 2012). In vitro, the Stars gene is more highly expressed in terminally differentiated skeletal myotubes than in proliferating myoblasts (Ounzain et al., 2008). Overexpressing STARS in porcine smooth muscle cells and in the A10 rat vascular smooth muscle cell line (Troidl et al., 2009) accelerates proliferation, supporting a role for STARS in muscle development.

Here we test the hypothesis that STARS may play a similar role in the regulation of skeletal muscle cell proliferation and extend our investigations to myotube differentiation. We report for the first time that STARS overexpression in $\mathrm{C} 2 \mathrm{C} 12$ mouse muscle cells enhances cell differentiation, but not proliferation, and upregulates the expression of several myogenic differentiation markers, differentiation factors and MRFs. CCG1423, a pharmacological inhibitor of SRF that limits the nuclear translocation of MRTF-A, did not attenuate basal or STARSinduced increase in differentiation rate, suggesting that STARS regulates $\mathrm{C} 2 \mathrm{C} 12$ cells differentiation via a MRTF-A-independent pathway.

\section{MATERIALS AND METHODS}

\section{Construction of pFLAG-mSTARS Expression Vector}

The cDNA for mouse STARS was subcloned into the pFLAGCMV4 (Sigma-Aldrich, Castle Hill, NSW) mammalian expression plasmid and was designated pFLAG-mSTARS. The DNA template used to produce the mouse STARS DNA fragment was the pBluescript-mouseSTARS plasmid, which was previously cloned by our group. Polymerase chain reaction (PCR) using specifically designed primers (Geneworks, Hindmarsh, SA) was performed to amplify the mouse STARS DNA sequence and incorporate the desired restriction enzyme sites, EcoRI, and BamHI. PCR products were separated on a $1.0 \%$ agarose gel and the $\sim 1000$ base mouse STARS DNA fragment was extracted and purified using the QIAquick Gel extraction Kit (QIAGEN, Doncaster, VIC). The mouse STARS DNA fragment and pFLAGCMV4 plasmid were digested using the EcoRI and BamHI restriction enzymes (NEB, Ipswich, MA) and subsequently ligated to produce the pFLAG-mSTARS plasmid. Amplification of pFLAG-mSTARS was achieved by transformation into 5- $\alpha$ Competent E. coli (High Efficiency) cells (NEB, Ipswich, MA) and plasmid DNA extraction and purification was performed using the QIAGEN plasmid kit (QIAGEN, Doncaster, VIC). Finally, automated sequencing (Applied Genetic Diagnostics, Parkville, VIC) was performed.

\section{Cell Culture}

C2C12 mouse myoblasts (ATCC, Manassas, VA) were maintained in complete Dulbecco's Modified Eagle's Medium (DMEM) supplemented with $10 \%$ fetal bovine serum (FBS; Life Technologies, Melbourne, Australia) at $37^{\circ} \mathrm{C}$ and $5 \% \mathrm{CO}_{2}$. For differentiation experiments, when cultures approached confluence ( $\sim 90 \%$ confluent), medium was changed to differentiation medium (DMEM) supplemented with $2 \%$ horse serum (HS; Life Technologies, Melbourne, Australia). Differentiation medium was replaced every $24 \mathrm{~h}$.

\section{Transient Transfection with pFLAG-mSTARS in C2C12 Myoblasts}

C2C12 myoblasts (1.0-2.0 $\times 10^{4}$ cells per well) were plated into six-well plates or $35 \mathrm{~mm} \mu$-Dishes (ibidi, Munich, Germany) $24 \mathrm{~h}$ before transfection. Myoblasts were transiently transfected with the pFLAG-mSTARS or pFLAG-CMV4 (Sigma-Aldrich, Castle Hill, NSW) plasmid using Lipofectamine 2000 (Life Technologies, Mulgrave, VIC). Myoblasts were exposed to transfection reagents for $24 \mathrm{~h}$, following what myoblasts were incubated in complete DMEM (10\% FBS) for $24 \mathrm{~h}$. RNA and protein were harvested for RT-PCR gene expression and western blot analysis, respectively. 


\section{MRTF-A/SRF Transcriptional Inhibition with CCG-1423 in C2C12 Myoblasts}

To provide proof-of concept that the pharmacological inhibitor CCG-1423 prevents MRTF-A translocation to the nucleus during all stages of $\mathrm{C} 2 \mathrm{C} 12$ cells differentiation, $2.0 \times 10^{4}$ or $2.0 \times$ $10^{5}$ myoblasts were plated in 6 well plates or $35 \mathrm{~mm} \mu$ Dishes (ibidi, Munich,Germany), respectively. Myoblasts were allowed to growth for $48 \mathrm{~h}$ in growth medium as described above, following what the medium was replaced by serumfree DMEM supplemented with either $5 \mu$ M CCG-1423 (Merck Millipore, Kilsyth, VIC) or dimethyl sulfoxide (DMSO) at a final concentration of $0.1 \%$. Similarly, myotubes were differentiated as described above and were serum-starved after either 48 or $96 \mathrm{~h}$ of differentiation. Following overnight incubation, the medium was changed to DMEM supplemented with $20 \%$ FBS containing the same concentrations of CCG-1423 or DMSO, respectively. After $1 \mathrm{~h}$, the cells were prepared for immuno-localisation.

\section{BrdU Assay}

The rate of $\mathrm{C} 2 \mathrm{C} 12$ myoblast proliferation was assessed using the colorimetric 5-bromo-2' -deoxy-uridine (BrdU) Labeling and Detection Kit III assay (Roche Applied Science, Indianapolis, USA) modified as follows. $\mathrm{C} 2 \mathrm{C} 12$ cells were plated at a concentration of $10^{4}$ cells $/ \mathrm{ml}$ in a 6-well tissue culture plate. Twenty-four hours later, myoblasts were transfected with pFLAG-mSTARS or pFLAG-CMV4 as described above, following what myoblasts were incubated in complete DMEM (10\% FBS) for $24 \mathrm{~h}$. Twenty-four hours before the analysis, the BrdU label reagent and CCG-1423 or DMSO treatment were added to the medium as described above. Nucleases were used to fragment DNA and BrdU incorporation into the DNA was detected using a horseradish peroxidase conjugated anti-BrdU antibody. Following the addition of the peroxidase substrate ABTS (2,2'-azino-bis, 3-ethylbenzthiazoline-6-sulphonic acid), fluorescence was detected at $405 \mathrm{~nm}$.

\section{DNA Synthesis Using Deuterated Water}

In addition to the BrdU cell proliferation assay, C2C12 myoblast proliferation was confirmed by measuring DNA synthesis using deuterated "heavy" water $\left({ }^{2} \mathrm{H}_{2} \mathrm{O}\right)$. The use of the stable isotopic tracer ${ }^{2} \mathrm{H}_{2} \mathrm{O}$ for measuring DNA synthesis has numerous advantages over other existing tracer methods including virtually no cell toxicity (at low ${ }^{2} \mathrm{H}_{2} \mathrm{O}$ concentrations, $<10 \%$ ), true precursor uniformity and greater tracing potential of the nucleotide synthesis pathways (Busch et al., 2007). C2C12 cells were prepared as described above for the BrdU assay. Twentyfour hours before the analysis, the culture medium containing $5 \%$ BSA was enriched with ${ }^{2} \mathrm{H}_{2} \mathrm{O}$ at a concentration of $4 \%$ and analysis performed as detailed previously (Kloehn et al., 2015). Briefly, 2000-5000 ng of cell nucleic acid was extracted, enzymatically hydrolyzed, and dephosphorylated (Busch et al., 2007) and the released nucleosides were derivatized with O-(2,3,4,5,6-pentafluorobenzyl) hydroxylamine hydrochloride (PFBHA HCl, $25 \mathrm{mg} / \mathrm{ml}$ in water; Sigma-Aldrich, Castle Hill, NSW) at $90^{\circ} \mathrm{C}, \mathrm{pH} 2$ for $3 \mathrm{~h}$. Deoxyribose sugars are released from nucleobases during oximation and their PFBHA derivative was extracted in ethyl acetate/hexane (1:1) and dried under nitrogen.
The dried samples were then silylated by addition of ethyl acetate $(20 \mu \mathrm{l})$ and N,O-bis(trimethylsilyl) trifluoroacetamide reagent $(40 \mu \mathrm{l}$ BSTFA + 1\% TMCS) (Thermo Scientific, Rockford, IL) and incubated at $90^{\circ} \mathrm{C}$ for $30 \mathrm{~min}$. The perfluorotritrimethylsilyl derivative of deoxyribose (MW: 545) was analyzed by GC/MS in positive chemical ionization mode using methane as reagent gas. The M0-M1 fragment ions $[\mathrm{M}+1-16]^{+}$of deoxyribose (530$531 \mathrm{~m} / \mathrm{z}$ ), corresponding to the loss of $\mathrm{CH}_{4}$, were analyzed and the excess M1 molar enrichments (EM1 \%) calculated (Busch et al., 2007; Kloehn et al., 2015).

\section{MRTF-A Cellular Localization}

To determine MRTF-A cell localization, myoblasts were fixed with $4 \%$ paraformaldehyde (PFA)/PBS for $10 \mathrm{~min}$ after incubation with DMEM supplemented with $20 \%$ FBS or serumfree DMEM for $1 \mathrm{~h}$. Cells were permeabilised in $0.1 \%$ Trition $\mathrm{X}-100 / \mathrm{PBS}$ for $5 \mathrm{~min}$ and blocked with $1 \%$ BSA/PBS for $1 \mathrm{~h}$ at room temperature. Cells were incubated overnight at $4{ }^{\circ} \mathrm{C}$ with a MRTF-A antibody (H-140) (sc-32909; Santa Cruz Biotechnology Inc, Dallas TX) diluted 1:500 in 1\% BSA/PBS and subsequently with an Alexa Fluor ${ }^{\circledR} 594$ goat anti-rabbit IgG secondary antibody (Life Technologies, Melbourne, VIC) diluted 1:1000 and $0.1 \mu \mathrm{g} / \mathrm{ml}$ DAPI stain (Sigma-Aldrich, Castle Hill, NSW) in $1 \%$ BSA/PBS for $1 \mathrm{~h}$ at room temperature. Cell images were obtained using the Olympus Fluoview FV10i confocal laser scanning microscope with dedicated software at a $150 \mathrm{x}$ magnification for myoblasts and at a $120 \mathrm{x}$ magnification for myotubes using consistent fluorescence thresholds and exposure times. The ratio between MRTF-A fluorescence in the nuclei against total MRTF-A fluorescence in the entire cell was calculated from a minimum of 10 images per group using the Image J software (U. S. National Institutes of Health, Bethesda).

\section{Adenoviral Infection with ADV-STARS}

Adenoviral constructs containing the mouse STARS (ADVSTARS) or the control gene LacZ (ADV-LacZ) were a generous gifts from Eric N. Olson, The University of Texas Southwestern Medical Center. C2C12 myoblasts were plated in six-well tissue culture plates or $35 \mathrm{~mm} \mu$-Dishes in complete DMEM (10\%FBS) and allowed to reach $\sim 90 \%$ confluence. Cells were infected with a multiplicity of infection (MOI) of 100 for both the ADVSTARS and the ADV-LacZ in differentiation medium (DMEM) supplemented with $2 \%$ HS. Cells were allowed to differentiate for 5 days and medium was replaced every $24 \mathrm{~h}$. RNA and protein were harvested at day 1,3 , and 5 of the differentiation process for RT-PCR gene expression and western blot analysis.

\section{Quantification of Myotube Fusion}

Following 5 days of differentiation, C2C12 myotubes were fixed with $4 \%$ PFA/PBS for $10 \mathrm{~min}$. Fixed cells were permeabilised in $0.1 \%$ Trition X-100/PBS and blocked with $1 \%$ BSA/PBS for $1 \mathrm{~h}$ at room temperature. Cells were incubated overnight at $4^{\circ} \mathrm{C}$ with a primary antibody against sarcomeric myosin (MF20, Developmental Studies Hybridoma Bank) diluted 1:50 in $1 \%$ BSA/PBS. Following this, the cells were incubated with an Alexa Fluor ${ }^{\circledR} 488$ goat anti-mouse IgG secondary antibody (Life Technologies, Melbourne, VIC) diluted $1: 1000$ and $0.1 \mu \mathrm{g} / \mathrm{ml}$ 
DAPI stain (Sigma-Aldrich, Castle Hill, NSW) in 1\% BSA/PBS for $1 \mathrm{~h}$ at room temperature. Cell images were obtained using the Olympus Fluoview FV10i confocal laser scanning microscope with dedicated software at a $20 \mathrm{x}$ magnification. To assess myogenic differentiation, the number of DAPI-stained nuclei within the sarcomeric myosin positive myotubes (multinucleated cells, i.e., $\geq 2$ nuclei) was determined and expressed as a percentage of the total number of nuclei analyzed per image. A minimum of 40 images per group (from two separate experiments) were analyzed using the Image Software (National Institutes of Health, Bethesda, MA).

\section{MRTF-A/SRF Transcriptional Inhibition with CCG-1423 in C2C12 Myotubes}

Confluent ( $90 \%)$ C2C12 myoblasts were infected with either the ADV-STARS or the vector control adenovirus (ADV-LacZ) as described above. The cells were then treated with either $5 \mu \mathrm{M}$ CCG-1423 (Merck Millipore, Kilsyth, VIC) or control vehicle (DMSO) in DMEM (2\%HS) for $24 \mathrm{~h}$. The final DMSO concentration in both treatments was $0.1 \%$. Cells were allowed to differentiate for 5 days and treatments were replaced every $24 \mathrm{~h}$.

\section{Cytotoxicity Assay}

Cytotoxicity of the SRF inhibitor CCG-1423 was assessed using the CellToxTM Green Cytotoxicity Assay (Promega, Auburn, VIC) according to the manufacturer's instructions. Briefly, C2C12 myoblasts were seeded at a density of $0.5 \times 10^{4}$ cells per well in back-walled 96-well tissue culture plates (ibidi, Munich, Germany) and grown in growth media for $48 \mathrm{~h}$. Myoblasts were then treated with $5 \mu \mathrm{M}$ CCG-1423 (Merck Millipore, Kilsyth, VIC) or $0.1 \%$ DMSO in serum free media for $24 \mathrm{~h}$. C2C12 myotubes were differentiated as described above. After $96 \mathrm{~h}$ of differentiation, the cells were treated with $5 \mu \mathrm{M}$ CCG-1423 (Merck Millipore, Kilsyth, VIC) or 0.1\% DMSO in serum free media for $24 \mathrm{~h}$ and fluorescence was measured at 485-500 nmEX/520-530 nmEM using a Synergy 2 multi-mode microplate reader (Biotek, Currumbin, QLD) to assess cell viability.

\section{RNA Extraction}

Total RNA was extracted using the Tri-Reagent ${ }^{\circledR}$ Solution (Ambion Inc, Austin TX) according to the manufacturer's protocol. First-strand cDNA was generated from 1 to $2 \mu \mathrm{g}$ RNA in $20 \mu \mathrm{L}$ reaction buffer using the High Capacity RNAto-cDNA kit (Applied Biosystems, Forster City, CA) according to the manufacturer's protocol. Before diluting $\mathrm{cDNA}, 1 \mu \mathrm{L}$ ribonuclease $\mathrm{H}$ (Rnase $\mathrm{H}$; Life Technolgies, Mulgrave, VIC) was added to each sample and incubated at $37^{\circ} \mathrm{C}$ for $30 \mathrm{~min}$. Following this, cDNA was diluted in NFW to $5 \mathrm{ng} / \mu \mathrm{L}$ and stored at $-20^{\circ} \mathrm{C}$ until further analysis.

\section{Real Time Quantitative PCR}

Real-time PCR was carried out using the Stratagene MX3000 PCR system (Agilent Technologies, Santa Clara CA) to measure the mRNA levels of genes of interest. To compensate for variations in input RNA amounts and efficiency of the reverse transcription, data was normalized to single-stranded DNA (ssDNA) content that was determined using the Quanti-iT OliGreen ssDNA Assay Kit (Molecular Probes, Eugene, OR). RT-PCR primer details for the mouse genes are provided in Table 1.

\section{Protein Extraction}

Total protein was extracted using 1x RIPA buffer (Millipore, North Ryde, NSW) with $1 \mu \mathrm{L} / \mathrm{mL}$ protease inhibitor cocktail (Sigma-Aldrich, Castle Hill, NSW) and $10 \mu \mathrm{L} / \mathrm{mL}$ Halt Phosphatase Inhibitor Single-Use Cocktail (Thermo Scientific, Rockford, IL). Total protein content was determined using the BCA Protein Assay Kit (Pierce Biotechnology, Rockford, IL) according to the manufacturer's instructions.

\section{Western Blotting}

Electrophoresis and protein transfer were performed using the XCell Surelock Novex Mini- Cell (Invitrogen, Carlsbad, CA) system. Protein lysates were separated by SDS-PAGE using pre-cast NuPAGE ${ }^{\circledR}$ Novex $4-12 \%$ Bis-Tris gels (Invitrogen, Carlsbad, CA) and transferred to a PVDF membrane (Millipore,

TABLE 1 | Details of mouse primers used for RT-PCR analysis.

\begin{tabular}{|c|c|c|c|}
\hline Gene & GenBank accession number & Forward Primer $\left(5^{\prime}-3^{\prime}\right)$ & Reverse primer $\left(5^{\prime}-3^{\prime}\right)$ \\
\hline Ckmt2 & NM_198415.2 & ACGCACTGGCCGAAGCATCC & GCCAGATCGCCCTTCAGGCC \\
\hline Fos & NM_010234.2 & CACTCCAAGCGGAGACAGAT & TGGGCTGCCAAAATAAACTC \\
\hline Igf1 & NM_010512.4 & GCTCTGCTTGCTCACCTTCAC & CCTCCGTCCACACACGAACT \\
\hline Lif & NM_008501.2 & GGCAACCTCATGAACCAGAT & ACCATCCGATACAGCTCCAC \\
\hline Myh4 & NM_010855.2 & ACAGACTAAAGTGAAAGCC & СTCTCAACAGAAAGATGGAT \\
\hline Myf5 & NM_008656.5 & CACCACAACCAACCCTAACCA & АСTCTCAATGTAGCGGATTGC \\
\hline Myf6 & NC_000076.6 & GGTACCCTATCCCCTTGCCA & GGGAGTTGCGTTCCTCTGA \\
\hline Sif & NM_020493.2 & ACGACCTTCAGCAAGAGGAA & AAGCCAGTGGCACTCATTCT \\
\hline
\end{tabular}


Billerica, MA). Membranes were then incubated at room temperature for $1 \mathrm{~h}$ in blocking buffer supplemented with $5 \%$ BSA/PBS. After blocking, membranes were incubated overnight at $4{ }^{\circ} \mathrm{C}$ with the following primary antibodies diluted 1:1000 in 5\% BSA/PBS: STARS (Institute of Medical and Veterinary Science, Adelaide SA); Myosin, Sarcomeric (MF-20, Developmental Studies Hybridoma Bank, Iowa City IA); SRF (Santa Cruz Biotechnology, Dallas, TX (sc-335)). Following washing the membranes were incubated for $1 \mathrm{~h}$ with the corresponding infrared dye-conjugated secondary antibodies (Thermo Fisher Scientific, Inc, Rockford, IL). After washing, the specific proteins were revealed using the Odyssey Imaging System (LI-COR, Lincoln, NE, USA). GAPDH (G8795, Sigma-Aldrich, Castle Hill, NSW) was used to control for protein loading and individual protein band optical densities were determined using the Odyssey Infrared Imaging System software.

\section{Statistical Analyses}

All data are reported as mean \pm SEM. To ensure homogeneity of variance, all data was log10-transformed and analyses were conducted on these transformed scales. Overexpression experiments in proliferating $\mathrm{C} 2 \mathrm{C} 12$ myoblasts were analyzed using either a two-tailed unpaired $t$-test or a one-way analysis of variance (ANOVA). For every other analysis, a mixed-model twoway ANOVA or a general ANOVA were used to compare group means using GenStat v16. Diagnostic plots of residuals and fitted values were checked to ensure homogeneity of variance (a key assumption for ANOVA). The least significant difference (LSD) test was used to compare pairs of means. The significance levels for both the F-tests in the ANOVA and the LSD tests were set at $p<0.05$. Note that the statistical significance reported in the figures is based on analysis of the transformed data but the reported means \pm S.E.M. are on the original (untransformed) scale.

\section{RESULTS}

\section{Endogenous Expression of STARS During Proliferation and Differentiation of $\mathrm{C}_{2} \mathrm{C} 12$ Myocytes}

Stars mRNA expression increased by 1.5 -fold in confluent myoblasts when compared to sub-confluent myoblasts $(p<0.001$; Figure 1A); however, there was no significant increase in STARS protein expression during myoblast proliferation (Figure 1B). Supplementary Figure 1 displays the full western blot images of all immunoblot pictures presented in this manuscript. Stars mRNA levels gradually increased
A

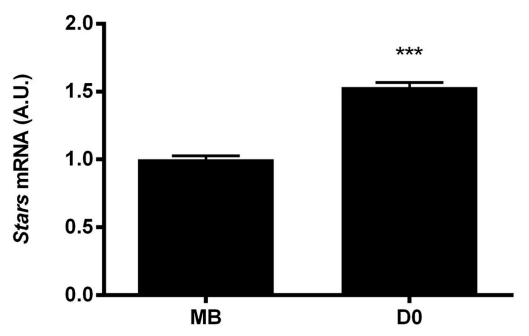

C

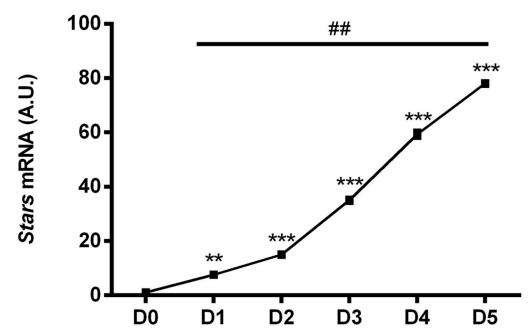

B
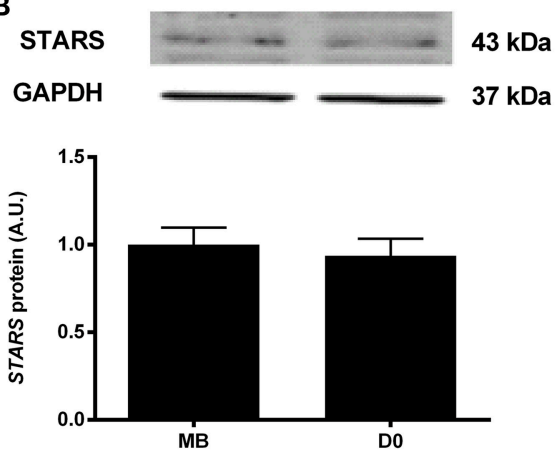

D
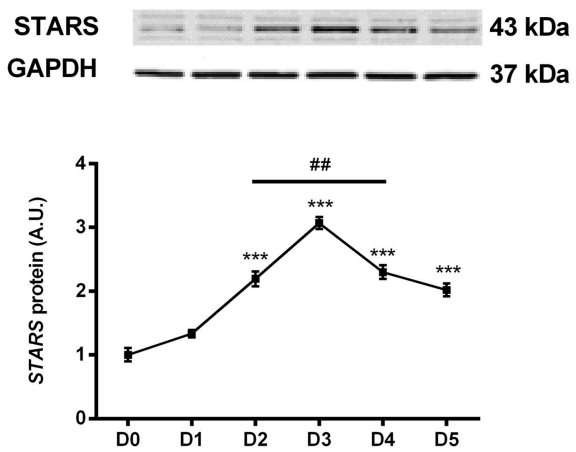

FIGURE 1 | STARS mRNA and protein expression levels were respectively measured by real-time qPCR and Western blot during C2C12 cells proliferation and differentiation. STARS mRNA (A) but not protein (B) levels increase in confluent myoblasts (DO; prior to adding differentiation media) when compared to sub confluent myoblasts (MB). ${ }^{* * *}$ different from MB, $p<0.001$. STARS mRNA (C) and protein (D) levels increase during myotube differentiation. ${ }^{* *}$ different from $\mathrm{D} 0, p<0.01$, ${ }^{\star \star *}$ different from $\mathrm{D} 0, p<0.001$, \#\# different from precedent day, $p<0.01$. 
during myotube differentiation to reach a 80 -fold increase by differentiation day 5 when compared to proliferating myoblasts (Figure 1C). When compared to D0, STARS protein levels concomitantly increased by 2 - to 3 -fold between differentiation days 2 and 5 (Figure 1D).

\section{The Effect of STARS Overexpression on SRF-Target Genes and C2C12 Myoblast Proliferation}

The overexpression of STARS in proliferating C2C12 myoblasts using a pFLAG-mSTARS plasmid (STARS) resulted in a substantial increase in Stars mRNA levels $(p<0.001)$ paralleled by a 15 -fold increase in STARS protein levels $(p<0.001)$ when compared to $\mathrm{C} 2 \mathrm{C} 12$ myoblasts transfected with a pFLAG-CMV4 plasmid (control) (Supplementary Figures 2A,B).

Immediate early genes function as early regulators of cell growth. In $\mathrm{C} 2 \mathrm{C} 12$ myoblasts overexpressing STARS, the expression levels of the known SRF-regulated immediate early genes Egrl and Junb increased when compared to control myoblasts (Figures 2A,B; compare white bars only). There was no effect of STARS on other early genes including Fos, Igf1 and Lif (data not shown). Analysis of both BrDU and deuterium incorporation assay did not reveal any difference in myoblast DNA synthesis with STARS overexpression. Thus, proliferation rates with STARS overexpression were unaltered (Figure 3 and Supplementary Figure 2C).

\section{The Effect of SRF Inhibitor CCG-1423 in C2C12 Myoblasts Overexpressing STARS}

Pharmacological SRF inhibitor CCG-1423 blocks the nuclear translocation of MRTF-A and therefore partially inhibits SRF activation. We aimed to determine if MRTF-A translocation was required for the STARS-induced increase in SRF target

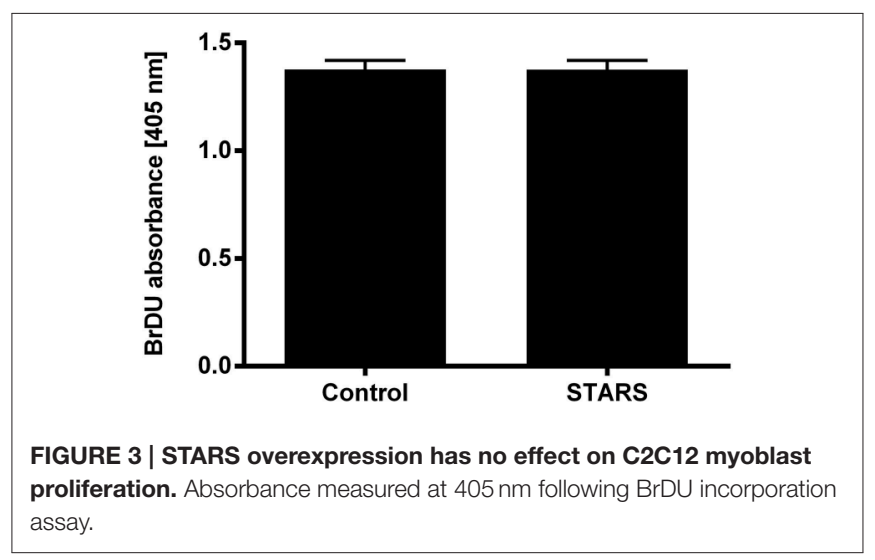

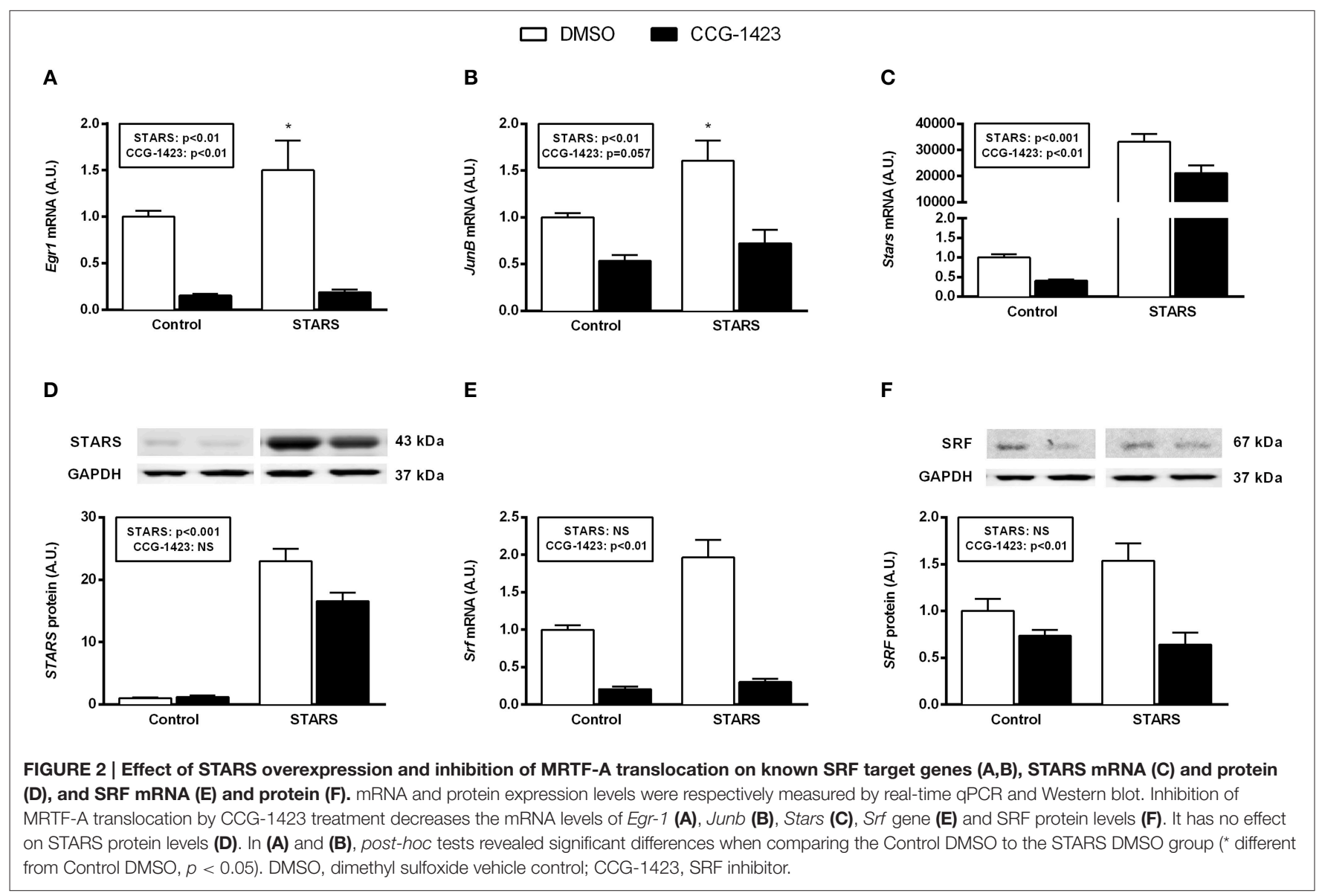


gene expression and if STARS overexpression was able to counteract the potential negative effect of the inhibitor. CCG1423 treatment had no cytotoxic effect on $\mathrm{C} 2 \mathrm{C} 12$ myoblasts when compared to DMSO treatment or to untreated myoblasts (Supplementary Figure 2D). In C2C12 myoblasts, MRTF-A is localized within the cytoplasm and the nucleus under serumfree and serum stimulated (20\% FBS) conditions. Following CCG-1423 treatment, we observed a decrease in MRTF-A presence in the nucleus in both conditions $(p<0.0001)$, providing proof-of-concept that CCG-1423 efficiently attenuates MRTF-A nuclear translocation in myoblasts (Figures 4A,B).

The expression levels of the SRF immediate early genes Egr1 and Junb were reduced following CCG-1423 treatment (main effect for treatment, $p<0.01$ and $p=0.06$, respectively); however, this decrease could not be prevented by STARS overexpression (Figures 2A,B). CCG-1423 treatment reduced endogenous Stars mRNA expression in control myoblasts (0.4fold; $p<0.01)$ and attenuated the increase in exogenous Stars in myoblasts transfected with the pFLAG-mSTARS plasmid (0.65fold; $p<0.01$; Figure 2C). These observations were paralleled by a significant decrease $(p<0.01)$ in exogenous but not in endogenous STARS protein expression levels (Figure 2D). SRF is known to regulate its own transcription. While Srf mRNA and SRF protein expression levels were not influenced by STARS overexpression, they were both significantly decreased following CCG-1423 treatment ( $p<0.01$; Figures 2E,F).

\section{The Effect of STARS Overexpression on C2C12 Myotube Differentiation}

STARS overexpression in $\mathrm{C} 2 \mathrm{C} 12$ myotubes resulted in a gradual increase in STARS mRNA and protein levels at differentiation days 3 and $5(p<0.05)$ when compared to control cells
(Figures 5A,B). An increase in differentiation rate following STARS overexpression was assessed both visually (Figure 5C) and by the calculation of the myotube fusion index that was higher in myotubes overexpressing STARS than in control myotubes $(p<0.001$; Figure 5D). In line with this result, STARS overexpression during differentiation increased the mRNA levels of the differentiation markers $\mathrm{Ckmt2}, \mathrm{Ckm}$ and $\mathrm{Myh} 4$ (MhcIIb), of the differentiation factor Igf2 and of the MRFs Myf5 and Myf6 (all $p<0.001$ ) (Figures 7A-E), but not of MyoG mRNA or protein levels (data not shown) when compared to control myotubes.

\section{The Effect of SRF Inhibitor CCG-1423 in C2C12 Myotubes Overexpressing STARS}

CCG-1423 treatment demonstrated no cytotoxic effect on C2C12 myotubes when compared to DMSO treatment or to untreated myotubes (Supplementary Figure 2E). Serum stimulation $(20 \%$ FBS) increased nuclear MRTF-A levels in C2C12 myotubes at differentiation day $3(p<0.05)$ (Figures 6A,B) but not at differentiation day 5 (Supplementary Figures $2 \mathrm{H}, \mathrm{G}$ ). At day 3 , this increase was attenuated when the cells were treated with CCG-1423 ( $p<0.0001)$, although MRTF-A presence in the nucleus also decreased to a smaller extend under serum-free conditions (Figure 6B). CCG-1423 treatment did not influence myotube differentiation rate in both control myotubes and myotubes overexpressing STARS (Figure 5D). CCG-1423 had no effect on $\mathrm{Ckmt2}, \mathrm{Ckm}, \mathrm{Myf5}, \mathrm{Myf6}$, Igf2 (Figures 7A-E) and Myog, Stars or Srf expression during differentiation (data not shown). On the other hand, post-hoc analyses revealed that in addition to a main treatment effect, CCG-1423 decreased Myh4 gene expression and $M H C$ protein levels at Day 3 and Day 5 in both groups (Figures 7F,G).

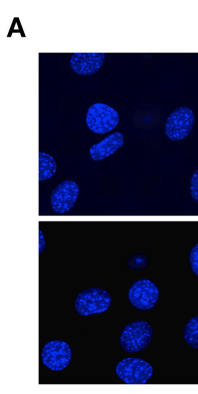

B
DMSO
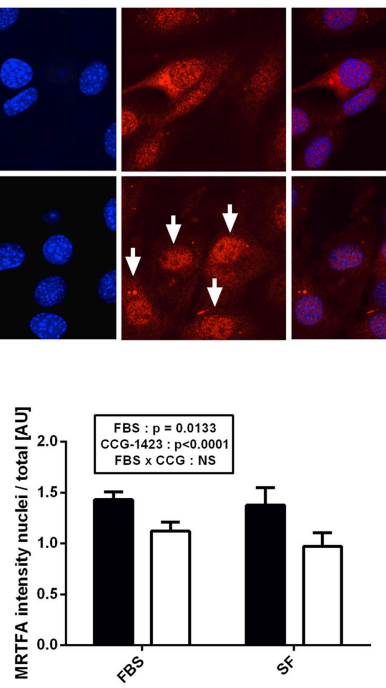

CCG-1423

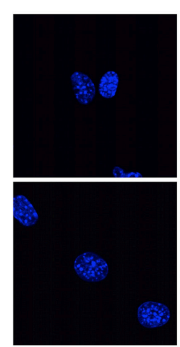

DAPI

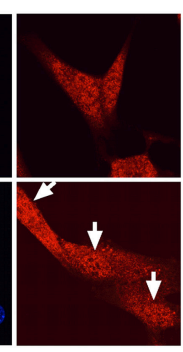

MRTF-A

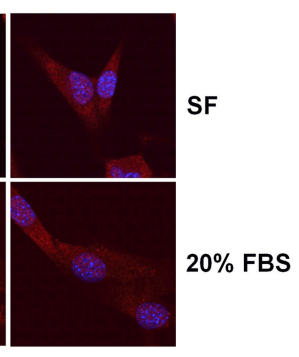

DAPI MRTF-A

FIGURE 4 | MRTF-A cellular localization following CCG-1234 treatment in serum-stimulated (20\% FBS) and serum-free (SF) C2C12 myoblasts. Immunolocalization of MRTF-A (A). Blue, DAPI staining; Red, MRTF-A; DMSO, dimethyl sulfoxide vehicle control; CCG-1423, SRF inhibitor. In the FBS treated group, arrows point toward the nuclei where MRTF-A presence is high (DMSO) or attenuated by CCG-1423 treatment (CCG-1423). MRTF-A intensity in the nucleus divided by total MRTF-A intensity (B). CCG-1423 treatment prevented MRTF-A nuclear translocation in both serum-stimulated (FBS) and serum-free (SF) C2C12 myoblasts. 


\section{A}

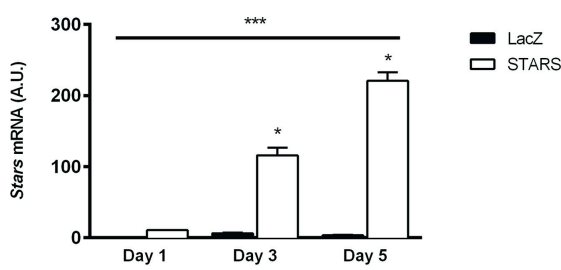

C

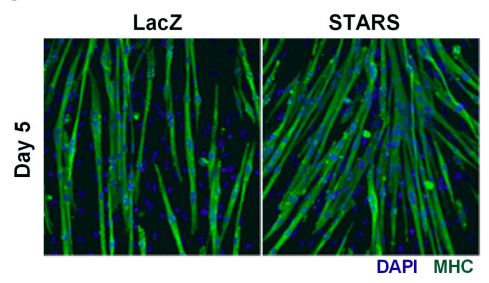

B STARS $\equiv \equiv=\equiv= \pm 43 \mathrm{ka}$

$\mathrm{GAPDH}-0-0-17 \mathrm{kDa}$

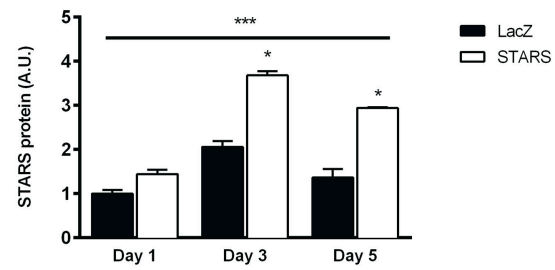

D

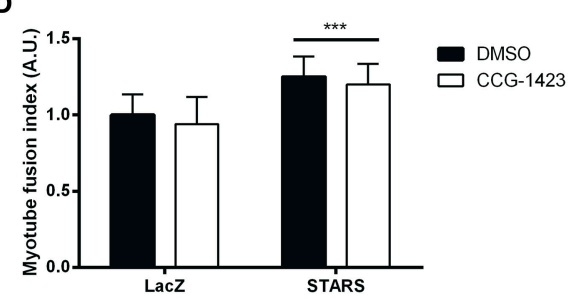

FIGURE 5 | STARS mRNA and protein levels gradually increase following overexpression in C2C12 myotubes and STARS overexpression accelerates myotube differentiation. mRNA and protein expression levels were respectively measured by real-time qPCR and Western blot. STARS mRNA (A) and protein (B) levels increase during 5 days of myotube differentiation. ${ }^{* \star *}$ Main effect of STARS overexpression, $p<0.001$. ${ }^{*}$ Significantly different from LacZ at the same time point, $p<0.05$. Immunofluorescent staining of MHC (green) and nuclei (blue) in differentiated myotubes at day 5 (C). Myotube fusion index at differentiation day 5 increases with STARS overexpression but is not influenced by CCG-1423 treatment (D). ${ }^{* *}$ Main effect of STARS overexpression, $p<0.001$.

A
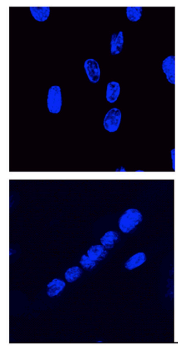

B

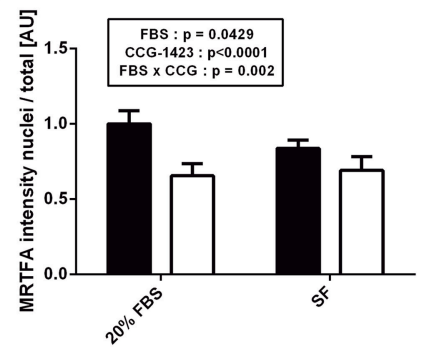

DMSO
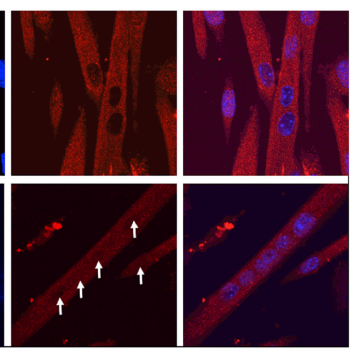

DMSO

CCG-1423

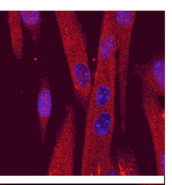

DAPI

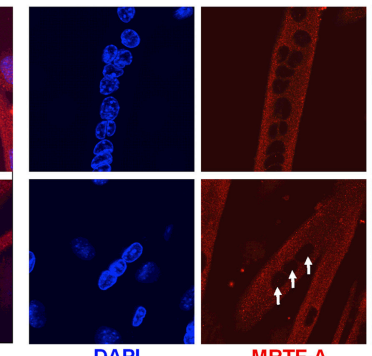

CCG-1423

MRTF-A

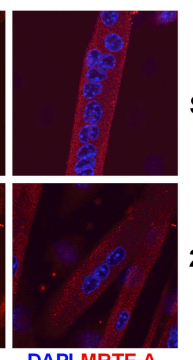

DAPI MRTF-A
SF

$20 \%$ FBS

FIGURE 6 | MRTF-A cellular localization following CCG-1234 treatment in serum-stimulated (20\% FBS) and serum-free (SF) C2C12 myotubes at differentiation day 3. Immunolocalization of MRTF-A (A). Blue, DAPI staining; Red, MRTF-A; DMSO, dimethyl sulfoxide vehicle control; CCG-1423, SRF inhibitor. In the FBS treated group, arrows point toward the nuclei where MRTF-A presence is high (DMSO) or attenuated by CCG-1423 treatment (CCG-1423). MRTF-A intensity in the nucleus divided by total MRTF-A intensity (B). Serum stimulation (FBS) increased MRTF-A presence in the nucleus when compared to serum-free (SF) conditions. CCG-1423 treatment prevented MRTF-A nuclear translocation in both serum-stimulated and serum-free C2C12 myotubes. 


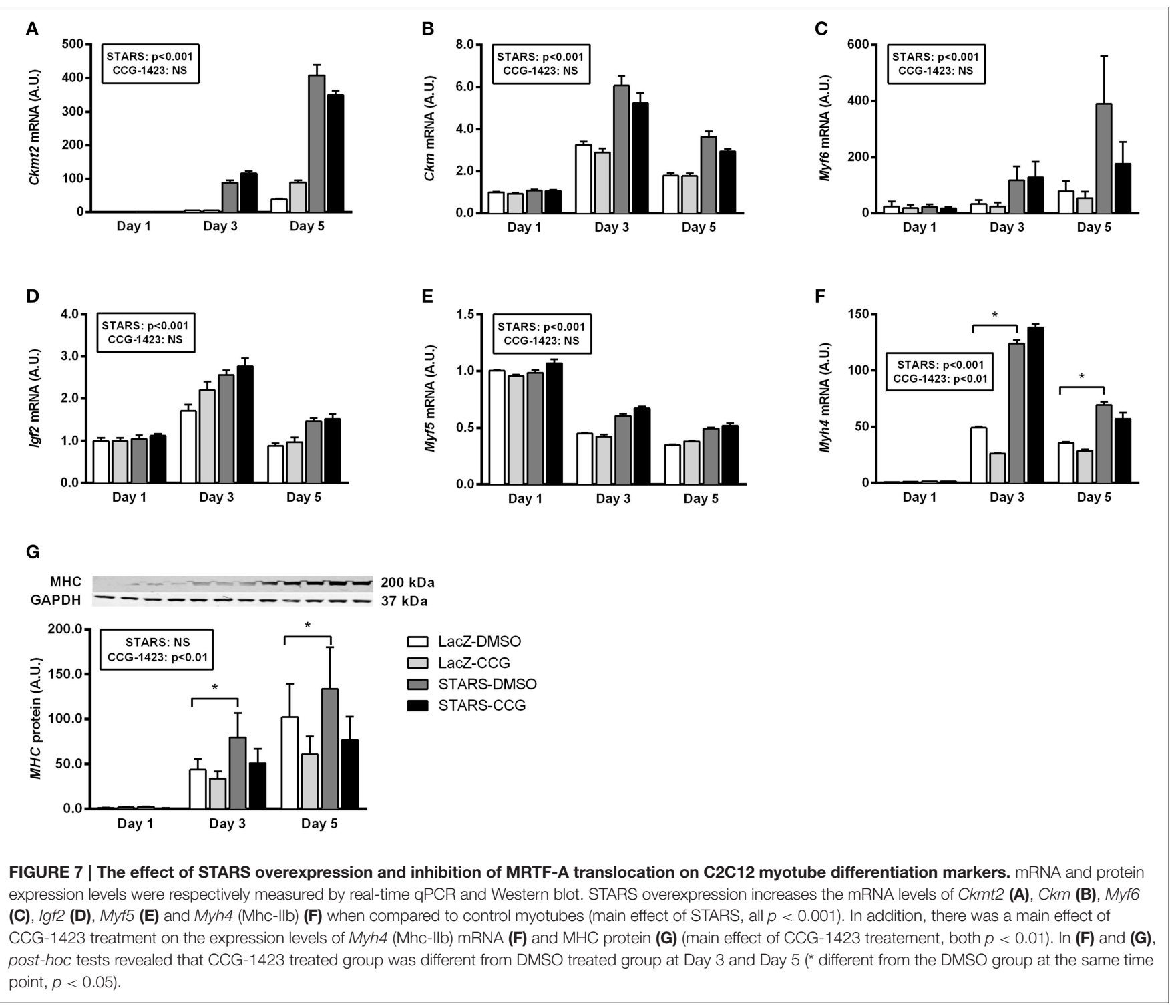

\section{DISCUSSION}

Skeletal muscle growth and regeneration is controlled by intracellular signals regulating myoblast proliferation and differentiation into mature multinucleated myotubes (Chambers and McDermott, 1996). The present study investigated whether STARS overexpression enhances the proliferation and differentiation of $\mathrm{C} 2 \mathrm{C} 12$ muscle cells. We demonstrate for the first time that overexpressing STARS at the onset of myoblast differentiation enhances skeletal muscle cell differentiation. The increase in myotube fusion index was paralleled by increases in the mRNA levels of the differentiation markers $\mathrm{Ckm}, \mathrm{Ckmt2}$, Myh4 (Mhc-IIb), of the differentiation factor Igf2 and of the MRFs Myf5 and Myf6 (MRF4). On the other hand, STARS overexpression had no effect on myoblast proliferation, although it increased the mRNA levels of the SRF immediate early genes Egr1 and Junb. While the pharmacological inhibitor of MRTF-A translocation CCG-1423 had a negative effect on SRF target gene expression, myotube differentiation rate was not attenuated.

The expression pattern of the STARS gene and protein during skeletal muscle cell proliferation and differentiation has only been partially investigated. In vivo, Stars starts to be expressed during the early embryonic development of skeletal muscle and continues to increase during post-natal muscle development (Peng et al., 2008). We observed an increase in Stars gene expression during myoblast proliferation and a further gradual increase during myotube differentiation, confirming previous observations made in $\mathrm{C} 2 \mathrm{C} 12$ cells (Ounzain et al., 2008). For the first time we extended these observations to the expression levels of the STARS protein, which significantly increased between differentiation day 2 and 5 . Together with our previous findings that STARS is required for myotube survival (Wallace and Russell, 2013), these observations suggest that increasing levels of STARS are necessary for optimal myocyte development. 
STARS activates SRF-dependant transcription by directly stimulating the promoters of genes regulated by SRF, such as Tagln2 (formerly Sm22- $\alpha$ ) and Acta1 (formerly $\alpha$-actin) (Arai et al., 2002). In skeletal muscle, SRF regulates cell growth via the transcription of immediate early genes such as Fos, Lif, Junb and Egr1 (Chai and Tarnawski, 2002; Pipes et al., 2006a; Miano et al., 2007); genes that enhance myoblast proliferation in L6 and $\mathrm{C} 2 \mathrm{C} 12$ cells (Rahm and Sejersen, 1990; Chalaux et al., 1998). In rat H9c2 cells, overexpressing STARS significantly increased the expression levels of several SRF target genes, including Junb, Lif and IL6 (Koekemoer et al., 2009; Chong et al., 2012). Here we report that STARS overexpression in skeletal muscle myoblasts increased the mRNA levels of some, but not all immediate early genes. STARS is however not the only signaling pathway able to activate SRF transcriptional activity. The MAPK pathway typically regulates the expression of SRF immediate early genes (Posern and Treisman, 2006; Sun et al., 2006; Muehlich et al., 2008) and STARS and MAPK signaling are believed to play exclusive but complementary roles in SRF transcriptional activation (Janknecht et al., 1993; Hill et al., 1995; Sotiropoulos et al., 1999; Gineitis and Treisman, 2001; Copeland and Treisman, 2002; Murai and Treisman, 2002). Our results support the observation (Selvaraj and Prywes, 2004) that the STARS pathway also influences SRF control of a subset of immediate early target genes, including Egr1 and Junb. Despite the positive regulation of the early regulators of gene growth Egr1 and Junb, STARS overexpression did not induce an increase in skeletal muscle cell proliferation. While STARS increases proliferation in porcine smooth muscle cells and in the A10 rat vascular smooth muscle cell line (Troidl et al., 2009), it has no effect on the proliferation of porcine aortic endothelial cells (Troidl et al., 2009) or of the H9c2 rat cardiac cell line (Koekemoer et al., 2009), suggesting cell- and species-specific influences.

We then investigated whether the STARS-induced increase in several SRF target genes was a direct consequence of STARS facilitating the nuclear translocation of the SRF transcriptional co-activator MRTF-A. The pharmacological SRF inhibitor CCG1423 inhibits MRTF-A co-activation of SRF transcriptional activity by preventing MRTF-A nuclear translocation. In H9c2 rat muscle cells, chromatin immunoprecipitation showed that CCG-1423 completely blocked STARS proximal reporter activity (Chong et al., 2012). In the present study, CCG-1423 treatment resulted in a significant decrease in the mRNA expression levels of the SRF target genes Egrl and Junb. This effect was independent of STARS expression levels, suggesting that supraphysiological levels of STARS in myoblasts are not sufficient to counteract the negative effect of CCG-1423. The effect of STARS on known SRF target gene expression may therefore not be via their direct regulation by STARS, but via STARS upstream regulation of the MRTF-A/SRF axis, supporting observations made in NIH 3T3 cells (Kuwahara et al., 2005). Of interest, one study showed that MRTF-A expression in pulmonary fibromyoblasts was SRF-dependant and was inhibited by CCG1423 treatment (Sandbo et al., 2011); findings that were not observed in $\mathrm{C} 2 \mathrm{C} 12$ myoblasts in the present study. Finally,
CCG-1423 treatment reduced Stars and Srf mRNA levels and $S R F$ protein levels, supporting the idea that (1) SRF can positively regulate its own transcription (Miano et al., 2007) and (2) STARS can also regulate its own transcription, which may require SRF binding to the SRE located on the STARS promoter; a binding that is completely prevented by the use of the CCG-1423 inhibitor (Chong et al., 2012).

Overexpressing STARS at the onset of myoblast differentiation enhanced myogenic differentiation in skeletal muscle cells as indicated by an increased fusion index and elevated levels of several known makers of myotube differentiation including creatine kinase and myosin heavy chain (Chamberlain et al., 1985; Brown et al., 2012) as well as the differentiation factor Igf2 (Florini et al., 1991; Magri et al., 1991) and the MRFs Myf5 and Myf6 but not MyoG. We showed that CCG-1423 prevented MRTF-A translocation to the nucleus in differentiating myotubes; however CCG-1423 treatment did not influence myotube differentiation in control cells or in STARS overexpressing cells. Nevertheless, it had a limited effect on some of the differentiation markers and caused a reduction in the expression levels of the $\mathrm{Ckm}$ gene and $\mathrm{MHC}$ protein at differentiation day 3 and day 5 in both control myotubes and myotubes overexpressing STARS. The $\mathrm{Ckm}$ gene is a SRF target gene possessing a CArG box that functions as a SRF-binding site in its cis-regulatory region (Vincent et al., 1993). Reduced SRF transcriptional activity negatively regulates the muscle creatine kinase $(\mathrm{Ckm})$ gene and mouse muscle lacking SRF display very low levels of $\mathrm{Ckm}$ (Charvet et al., 2006). As CCG-1423 did not prevent MRTF-A translocation in myotubes at differentiation day 5 , it is likely that the observed effects on myosin heavy chain gene and protein expression levels were carried on from an earlier time point. Altogether, these results support the hypothesis that skeletal muscle cell differentiation is marginally under the control of the MRTFA/SRF transcriptional pathway and suggest the existence of a mechanism that functions in parallel and/or complementary to MRTF-A.

It is known that STARS influences SRF-mediated gene transcription via a mechanism involving RhoA signaling (Arai et al., 2002); a pathway that is essential for the differentiation of smooth, cardiac and skeletal muscle cells (Aoki et al., 1998; Du et al., 2004). The precise mechanism underlying the STARS-RhoA interaction is unknown. However, in nonmuscle cells, STARS and RhoA can act independent of each other and individually enhance SRF transcriptional activity (Arai et al., 2002), although their combined overexpression augments this effect. Our results indicate that STARS plays an essential role in the differentiation from myoblasts to mature myotubes; to which extent this process is mediated by RhoA is unknown. Another hypothesis relies on observations reporting that $\mathrm{Z}$ disc proteins, such as calsarcin-1, can negatively regulate calcineurin/NFAT (nuclear factor of activated T cells) signaling in cardiac tissue (Frey et al., 2004; Gautel, 2008). Calcineurin plays an important regulatory role in skeletal muscle remodeling (Ryder et al., 2005) via the activation of transduction pathways involving calcium-calmodulin-dependent protein kinase IV (CaMKIV; Wu et al., 2002), MEF-2 and PGC-1 $\alpha$ (Lin et al., 
2002). STARS may activate a calcium-dependent regulatory pathway that assists with cell differentiation, however this has not been experimentally validated. In both cases, the lack of effect of CCG-1423 treatment on myotube fusion index suggests that MRTF-A would not be an obligatory part of these mechanisms.

\section{CONCLUSION}

In conclusion, we show for the first time that STARS overexpression enhances the differentiation process in mouse C2C12 muscle cells. Overexpression of STARS in proliferating C2C12 myoblasts was associated with increased expression of SRF target genes involved in muscle cell growth but did not lead to increased proliferation. STARS overexpression in differentiating myotubes was associated with increased expression of typical and muscle-specific differentiation genes associated with cell structure and metabolism. STARS-induced increase in myotube differentiation was not influenced by CCG1423 treatment, suggesting that STARS-mediated control of differentiation may also be via an MRTF-A/SRF independent mechanism. Overall, these in vitro findings position STARS as an important potential regulator of skeletal muscle growth and regeneration and this now requires experimental in vivo validation in an appropriate mouse model.

\section{AUTHOR CONTRIBUTIONS}

Designed the study: MW, AR, SL. Completed the experiments: MW, PD, BA, GK, JK, SL. Analyzed the data: MW, PG, GK, SL. Wrote and reviewed the manuscript: all authors. Funded the study: MM, AR, SL.

\section{REFERENCES}

Aoki, H., Izumo, S., and Sadoshima, J. (1998). Angiotensin II activates RhoA in cardiac myocytes: a critical role of RhoA in angiotensin II-induced premyofibril formation. Circ. Res. 82, 666-676. doi: 10.1161/01.RES.82.6.666

Arai, A., Spencer, J. A., and Olson, E. N. (2002). STARS, a striated muscle activator of Rho signaling and serum response factor-dependent transcription. J. Biol. Chem. 277, 24453-24459. doi: 10.1074/jbc.M202216200

Bentzinger, C. F., Wang, Y. X., and Rudnicki, M. A. (2012). Building muscle: molecular regulation of myogenesis. Cold Spring Harb. Perspect. Biol. 4:a008342. doi: 10.1101/cshperspect.a008342

Black, B. L., and Olson, E. N. (1998). Transcriptional control of muscle development by myocyte enhancer factor-2 (MEF2) proteins. Annu. Rev. Cell Dev. Biol. 14, 167-196. doi: 10.1146/annurev.cellbio.14.1.167

Brown, D. M., Parr, T., and Brameld, J. M. (2012). Myosin heavy chain mRNA isoforms are expressed in two distinct cohorts during $\mathrm{C} 2 \mathrm{C} 12$ myogenesis. J. Muscle Res. Cell Motil. 32, 383-390. doi: 10.1007/s10974-011-9267-4

Buckingham, M., Bajard, L., Chang, T., Daubas, P., Hadchouel, J., Meilhac, S., et al. (2003). The formation of skeletal muscle: from somite to limb. J. Anat. 202, 59-68. doi: 10.1046/j.1469-7580.2003.00139.x

Busch, R., Neese, R. A., Awada, M., Hayes, G. M., and Hellerstein, M. K. (2007). Measurement of cell proliferation by heavy water labeling. Nat. Protoc. 2, 3045-3057. doi: 10.1038/nprot.2007.420

Chai, J., and Tarnawski, A. S. (2002). Serum response factor: discovery, biochemistry, biological roles and implications for tissue injury healing. J. Physiol. Pharmacol. 53, 147-157.

\section{ACKNOWLEDGMENTS}

The MHC antibody (MF20) developed by Donald A. Fischman was obtained from the Developmental Studies Hybridoma Bank, created by the NICHD of the NIH and maintained at The University of Iowa, Department of Biology, Iowa City, IA 52242. SL was supported by an Alfred Deakin Postdoctoral Fellowship from Deakin University and a Discovery Early Career Researcher Award (DECRA) from the Australian Research Council. This work was supported by the National Health and Medical Research Council (NH\&MRC) (grant 1046501) to AR. MW's current affiliation is Department of Neurobiology, Physiology and Behavior, University of California Davis, Davis, California, USA.

\section{SUPPLEMENTARY MATERIAL}

The Supplementary Material for this article can be found online at: http://journal.frontiersin.org/article/10.3389/fphys. 2016.00007

Supplementary Figure 1 | Full western blot images of all immunoblot pictures presented in the manuscript.

Supplementary Figure 2 | (A) STARS mRNA levels following STARS overexpression in $\mathrm{C} 2 \mathrm{C} 12$ myoblasts. (B) STARS protein levels following STARS overexpression in $\mathrm{C} 2 \mathrm{C} 12$ myoblasts. (C) ${ }^{2} \mathrm{H}$ Enrichment expressed as a percentage of EM1 following deuterium incorporation assay. (D) Absorbance measured at $485 \mathrm{~nm}$ following a cytotoxicity assay in C2C12 myoblasts. (E) Absorbance measured at $485 \mathrm{~nm}$ following a cytotoxicity assay in $\mathrm{C} 2 \mathrm{C} 12$ myotubes. (H) MRTF-A cellular localization following CCG-1234 treatment in serum-stimulated (20\% FBS) and serum-free (SF) C2C12 myotubes at differentiation day 5. Immunolocalization of MRTF-A. Blue, DAPI staining; Red, MRTF-A; DMSO, dimethyl sulfoxide vehicle control; CCG-1423, SRF inhibitor. (G) MRTF-A intensity in the nucleus divided by total MRTF-A intensity in $\mathrm{C} 2 \mathrm{C} 12$ myotubes at differentiation day 5 .
Chalaux, E., López-Rovira, T., Rosa, J. L., Bartrons, R., and Ventura, F. (1998). JunB is involved in the inhibition of myogenic differentiation by bone morphogenetic protein-2. J. Biol. Chem. 273, 537-543. doi: $10.1074 /$ jbc. 273.1 .537

Chamberlain, J. S., Jaynes, J. B., and Hauschka, S. D. (1985). Regulation of creatine kinase induction in differentiating mouse myoblasts. Mol. Cell. Biol. 5, 484-492. doi: 10.1128/MCB.5.3.484

Chambers, R. L., and McDermott, J. C. (1996). Molecular basis of skeletal muscle regeneration. Can. J. Appl. Physiol. 21, 155-184. doi: 10.1139/h96-014

Charvet, C., Houbron, C., Parlakian, A., Giordani, J., Lahoute, C., Bertrand, A., et al. (2006). New role for serum response factor in postnatal skeletal muscle growth and regeneration via the interleukin 4 and insulin-like growth factor 1 pathways. Mol. Cell. Biol. 26, 6664-6674. doi: 10.1128/MCB.00138-06

Chong, N. W., Koekemoer, A. L., Ounzain, S., Samani, N. J., Shin, J. T., and Shaw, S. Y. (2012). STARS is essential to maintain cardiac development and function in vivo via a SRF pathway. PLoS ONE 7:e40966. doi: 10.1371/journal.pone.0040966

Copeland, J. W., and Treisman, R. (2002). The diaphanous-related formin mDial controls serum response factor activity through its effects on actin polymerization. Mol. Biol. Cell 13, 4088-4099. doi: 10.1091/mbc.02-06-0092

Du, K. L., Chen, M., Li, J., Lepore, J. J., Mericko, P., and Parmacek, M. S. (2004). Megakaryoblastic leukemia factor-1 transduces cytoskeletal signals and induces smooth muscle cell differentiation from undifferentiated embryonic stem cells. J. Biol. Chem. 279, 17578-17586. doi: 10.1074/jbc.M400961200

Florini, J. R., Magri, K. A., Ewton, D. Z., James, P. L., Grindstaff, K., and Rotwein, P. S. (1991). "Spontaneous" differentiation of skeletal myoblasts is dependent 
upon autocrine secretion of insulin-like growth factor-II. J. Biol. Chem. 266, 15917-15923.

Frey, N., Barrientos, T., Shelton, J. M., Frank, D., Rütten, H., Gehring, D., et al. (2004). Mice lacking calsarcin-1 are sensitized to calcineurin signaling and show accelerated cardiomyopathy in response to pathological biomechanical stress. Nat. Med. 10, 1336-1343. doi: 10.1038/nm1132

Gautel, M. (2008). The sarcomere and the nucleus: functional links to hypertrophy, atrophy and sarcopenia. Adv. Exp. Med. Biol. 642, 176-191. doi: 10.1007/9780-387-84847-1_13

Gineitis, D., and Treisman, R. (2001). Differential usage of signal transduction pathways defines two types of serum response factor target gene. J. Biol. Chem. 276, 24531-24539. doi: 10.1074/jbc.M102678200

Handschin, C., Rhee, J., Lin, J., Tarr, P. T., and Spiegelman, B. M. (2003). An autoregulatory loop controls peroxisome proliferator-activated receptor gamma coactivator lalpha expression in muscle. Proc. Natl. Acad. Sci. U.S.A. 100, 7111-7116. doi: 10.1073/pnas. 1232352100

Hill, C. S., Wynne, J., and Treisman, R. (1995). The Rho family GTPases RhoA, Racl, and CDC42Hs regulate transcriptional activation by SRF. Cell 81, 1159-1170. doi: 10.1016/S0092-8674(05)80020-0

Janknecht, R., Ernst, W. H., Pingoud, V., and Nordheim, A. (1993). Activation of ternary complex factor Elk-1 by MAP kinases. EMBO J. 12, 5097-5104.

Kablar, B., Krastel, K., Ying, C., Asakura, A., Tapscott, S. J., and Rudnicki, M. A. (1997). MyoD and Myf-5 differentially regulate the development of limb versus trunk skeletal muscle. Development 124, 4729-4738.

Kloehn, J., Saunders, E. C., O’Callaghan, S., Dagley, M. J., and McConville, M. J. (2015). Characterization of metabolically quiescent Leishmania parasites in murine lesions using heavy water labeling. PLoS Pathog. 11:e1004683. doi: 10.1371/journal.ppat.1004683

Koekemoer, A. L., Chong, N. W., Goodall, A. H., and Samani, N. J. (2009). Myocyte stress 1 plays an important role in cellular hypertrophy and protection against apoptosis. FEBS Lett. 583, 2964-2967. doi: 10.1016/j.febslet.2009.08.011

Kuwahara, K., Barrientos, T., Pipes, G. C. T., Li, S., and Olson, E. N. (2005). Muscle-specific signaling mechanism that links actin dynamics to serum response factor. Mol. Cell. Biol. 25, 3173-3181. doi: 10.1128/MCB.25.8.31733181.2005

Kuwahara, K., Teg Pipes, G. C., McAnally, J., Richardson, J. A., Hill, J. A., BasselDuby, R., et al. (2007). Modulation of adverse cardiac remodeling by STARS, a mediator of MEF2 signaling and SRF activity. J. Clin. Invest. 117, 1324-1334. doi: 10.1172/JCI31240

Lamon, S., Wallace, M. A., Léger, B., and Russell, A. P. (2009). Regulation of STARS and its downstream targets suggest a novel pathway involved in human skeletal muscle hypertrophy and atrophy. J. Physiol. 587, 1795-1803. doi: 10.1113/jphysiol.2009.168674

Li, S., Czubryt, M. P., McAnally, J., Bassel-Duby, R., Richardson, J. A., Wiebel, F. F., et al. (2005). Requirement for serum response factor for skeletal muscle growth and maturation revealed by tissue-specific gene deletion in mice. Proc. Natl. Acad. Sci. U.S.A. 102, 1082-1087. doi: 10.1073/pnas.0409103102

Lin, J., Wu, H., Tarr, P. T., Zhang, C. Y., Wu, Z., Boss, O., et al. (2002). Transcriptional co-activator PGC-1 alpha drives the formation of slow-twitch muscle fibres. Nature 418, 797-801. doi: 10.1038/nature00904

MacNeil, L. G., Melov, S., Hubbard, A. E., Baker, S. K., and Tarnopolsky, M. A. (2010). Eccentric exercise activates novel transcriptional regulation of hypertrophic signaling pathways not affected by hormone changes. PLOS ONE 5:e10695. doi: 10.1371/journal.pone.0010695

Magri, K. A., Ewton, D. Z., and Florini, J. R. (1991). The role of the IGFs in myogenic differentiation. Adv. Exp. Med. Biol. 293, 57-76. doi: 10.1007/9781-4684-5949-4_6

Mahadeva, H., Brooks, G., Lodwick, D., Chong, N. W., and Samani, N. J. (2002). msl, a novel stress-responsive, muscle-specific gene that is up-regulated in the early stages of pressure overload-induced left ventricular hypertrophy. FEBS Lett. 521, 100-104. doi: 10.1016/S0014-5793(02)02833-8

Miano, J. M., Long, X., and Fujiwara, K. (2007). Serum response factor: master regulator of the actin cytoskeleton and contractile apparatus. Am. J. Physiol. Cell Physiol. 292, C70-C81. doi: 10.1152/ajpcell.00386.2006

Muehlich, S., Wang, R., Lee, S. M., Lewis, T. C., Dai, C., and Prywes, R. (2008). Serum-induced phosphorylation of the serum response factor coactivator MKL1 by the extracellular signal-regulated kinase $1 / 2$ pathway inhibits its nuclear localization. Mol. Cell. Biol. 28, 6302-6313. doi: 10.1128/MCB.00 427-08

Murai, K., and Treisman, R. (2002). Interaction of serum response factor (SRF) with the Elk-1 B box inhibits RhoA-actin signaling to SRF and potentiates transcriptional activation by Elk-1. Mol. Cell. Biol. 22, 7083-7092. doi: 10.1128/MCB.22.20.7083-7092.2002

Murray, J., and Huss, J. M. (2011). Estrogen-related receptor alpha regulates skeletal myocyte differentiation via modulation of the ERK MAP kinase pathway. Am. J. Physiol. Cell Physiol. 301, C630-C645. doi: 10.1152/ajpcell.00033.2011

Naya, F. J., and Olson, E. (1999). MEF2: a transcriptional target for signaling pathways controlling skeletal muscle growth and differentiation. Curr. Opin. Cell Biol. 11, 683-688. doi: 10.1016/S0955-0674(99)0 0036-8

Ounzain, S., Dacwag, C. S., Samani, N. J., Imbalzano, A. N., and Chong, N. W. (2008). Comparative in silico analysis identifies bona fide MyoD binding sites within the Myocyte stress 1 gene promoter. BMC Mol. Biol. 9:50. doi: 10.1186/1471-2199-9-50

Peng, Y. B., Guan, H. P., Fan, B., Zhao, S. H., Xu, X. W., Li, K., et al. (2008). Molecular characterization and expression pattern of the porcine STARS, a striated muscle-specific expressed gene. Biochem. Genet. 46, 644-651. doi: 10.1007/s10528-008-9178-2

Perry, R. L., and Rudnick, M. A. (2000). Molecular mechanisms regulating myogenic determination and differentiation. Front. Biosci. 5, D750-D767. doi: 10.2741/Perry

Pipes, G. C., Creemers, E. E., and Olson, E. N. (2006a). The myocardin family of transcriptional coactivators: versatile regulators of cell growth, migration, and myogenesis. Genes Dev. 20, 1545-1556. doi: 10.1101/gad.14 28006

Pipes, G. C. T., Creemers, E. E., and Olson, E. N. (2006b). The myocardin family of transcriptional coactivators: versatile regulators of cell growth, migration, and myogenesis. Genes Dev. 20, 1545-1556. doi: 10.1101/gad.1428006

Posern, G., and Treisman, R. (2006). Actin' together: serum response factor, its cofactors and the link to signal transduction. Trends Cell Biol. 16, 588-596. doi: 10.1016/j.tcb.2006.09.008

Rahm, M., and Sejersen, T. (1990). c-fos reduces growth factor requirements for mitogenic stimulation of L6 rat myoblasts. J. Cell. Physiol. 142, 352-358. doi: 10.1002/jcp. 1041420218

Ryder, J. W., Long, Y. C., Nilsson, E., Mahlapuu, M., and Zierath, J. R. (2005). Effects of calcineurin activation on insulin-, AICAR- and contractioninduced glucose transport in skeletal muscle. J. Physiol. 567, 379-386. doi: 10.1113/jphysiol.2005.090829

Sandbo, N., Lau, A., Kach, J., Ngam, C., Yau, D., and Dulin, N. O. (2011). Delayed stress fiber formation mediates pulmonary myofibroblast differentiation in response to TGF-beta. Am. J. Physiol. Lung Cell. Mol. Physiol. 301, L656-L666. doi: 10.1152/ajplung.00166.2011

Selvaraj, A., and Prywes, R. (2004). Expression profiling of serum inducible genes identifies a subset of SRF target genes that are MKL dependent. BMC Mol. Biol. 5:13. doi: 10.1186/1471-2199-5-13

Sotiropoulos, A., Gineitis, D., Copeland, J., and Treisman, R. (1999). Signalregulated activation of serum response factor is mediated by changes in actin dynamics. Cell 98, 159-169. doi: 10.1016/S0092-8674(00)81011-9

Soulez, M., Rouviere, C. G., Chafey, P., Hentzen, D., Vandromme, M., Lautredou, N., et al. (1996). Growth and differentiation of C2 myogenic cells are dependent on serum response factor. Mol. Cell. Biol. 16, 6065-6074. doi: 10.1128/MCB.16.11.6065

Sun, Q., Chen, G., Streb, J. W., Long, X., Yang, Y., Stoeckert, C. J. Jr., et al. (2006). Defining the mammalian CArGome. Genome Res. 16, 197-207. doi: $10.1101 /$ gr.4108706

Troidl, K., Rüding, I., Cai, W. J., Mücke, Y., Grossekettler, L., Piotrowska, I., et al. (2009). Actin-binding rho activating protein (Abra) is essential for fluid shear stress-induced arteriogenesis. Arterioscler. Thromb. Vasc. Biol. 29, 2093-2101. doi: 10.1161/ATVBAHA.109.195305

Vincent, C. K., Gualberto, A., Patel, C. V., and Walsh, K. (1993). Different regulatory sequences control creatine kinase- $\mathrm{M}$ gene expression in directly injected skeletal and cardiac muscle. Mol. Cell. Biol. 13, 1264-1272. doi: 10.1128/MCB.13.2.1264 
Wallace, M. A., Hock, M. B., Hazen, B. C., Kralli, A., Snow, R. J., and Russell, A. P. (2011). Striated muscle activator of Rho signalling (STARS) is a PGClalpha/oestrogen-related receptor-alpha target gene and is upregulated in human skeletal muscle after endurance exercise. J. Physiol. 589, 2027-2039. doi: 10.1113/jphysiol.2011.205468

Wallace, M. A., and Russell, A. P. (2013). Striated muscle activator of Rho signaling (STARS) is required for myotube survival but does not influence basal protein synthesis or degradation. Am. J. Physiol. Cell Physiol. 305, C414-C426. doi: 10.1152/ajpcell.00421.2012

Wu, H., Kanatous, S. B., Thurmond, F. A., Gallardo, T., Isotani, E., Bassel-Duby, R., et al. (2002). Regulation of mitochondrial biogenesis in skeletal muscle by CaMK. Science 296, 349-352. doi: 10.1126/science.1071163

Yokoyama, S., and Asahara, H. (2011). The myogenic transcriptional network. Cell. Mol. Life Sci. 68, 1843-1849. doi: 10.1007/s00018-011-0629-2

Zhang, W., Behringer, R. R., and Olson, E. N. (1995). Inactivation of the myogenic bHLH gene MRF4 results in up-regulation of myogenin and rib anomalies. Genes Dev. 9, 1388-1399. doi: 10.1101/gad.9.11.1388
Zhang, X., Chai, J., Azhar, G., Sheridan, P., Borras, A. M., Furr, M. C., et al. (2001). Early postnatal cardiac changes and premature death in transgenic mice overexpressing a mutant form of serum response factor. J. Biol. Chem. 276, 40033-40040. doi: 10.1074/jbc.M1049 34200

Conflict of Interest Statement: The authors declare that the research was conducted in the absence of any commercial or financial relationships that could be construed as a potential conflict of interest.

Copyright $\odot 2016$ Wallace, Della Gatta, Ahmad Mir, Kowalski, Kloehn, McConville, Russell and Lamon. This is an open-access article distributed under the terms of the Creative Commons Attribution License (CC BY). The use, distribution or reproduction in other forums is permitted, provided the original author(s) or licensor are credited and that the original publication in this journal is cited, in accordance with accepted academic practice. No use, distribution or reproduction is permitted which does not comply with these terms. 